\title{
Examination by electron microscopy of the San Carlos viruses isolated from children with infectious hepatitis
}

\author{
A. J. ZUCKERMAN, R. G. BIRD, LORNA J. DUNKLEY, AND G. J. LOVE
}

From the London School of Hygiene and Tropical Medicine, London, and the National Communicable Disease Center, Public Health Service, Atlanta, Georgia, USA

SYNOPSIS The results of a study by electron microscopy of the cytopathic effects produced by the San Carlos viruses on cultured human embryo hepatocytes are reported. Examination of liver cell $\$$ infected with San Carlos virus 6 revealed single virions and crystalline arrays with the hexagonal virion contour measuring an average of 65 to $70 \mathrm{~m} \mu$. However, associated with this predominan virion a smaller virus particle with a dimension of 30 to $40 \mathrm{~m} \mu$ was also found. The nature of the second virion type is not yet clear but its diameter is much larger than the size so far described for the adeno-associated viruses. The size of the smaller virion is probably also too large for it to be serious candidate for the hepatitis virus but the possible role of these agents in the aetiology of infectious hepatitis, at least in some patients, merits further study.

Davis (1961) reported the isolation of cytopathic agents from faecal specimens obtained from young Indian children admitted to hospital with infectious hepatitis during an outbreak on the San Carlos Apache Indian reservation in eastern Arizona in the autumn of 1959. Similar viruses were isolated two years later from an epidemic in another Indian reservation. These cytopathic agents could not be readily identified and consequently have been named the San Carlos viruses. Subsequent studies showed that 12 of the 14 strains isolated from 22 children involved in the San Carlos outbreak were neutralized by adenovirus types 1,2 , or 3 . However, the adenovirus type 3 strains, to which the majority of the isolates belonged, differed from the prototype adenovirus 3 in their homologous and heterologous neutralization titres and by the haemagglutinationinhibition test (Hatch and Siem, 1966), by their resistance to inactivation by heat (Davis, 1961), and by the cytopathic changes produced in cultures of human embryo liver cells (Zuckerman, Dunkley, and Love, 1968). The electron microscope was used in a preliminary study of the effect of a number of these agents on human embryo hepatocytes in culture. Results of this study are reported as well as the results of a search for an associated second agent.

Received for publication 16 May 1968.
MATERIALS AND METHODS

Primary cultures of human embryo hepatocytes were prepared as described previously by Zuckerman, Tsiquay and Fulton (1967b). The cell cultures were incubated at $35^{\circ} \mathrm{C}$ in an atmosphere containing $2 \% \mathrm{CO}_{2}$ and the were used for the experimental work usually withm 48 hours.

Four of the San Carlos viruses were used in this stud跍, namely, SC-3, SC-6, SC-8, and SC-49, all of which were found to be closely related serologically to adenovir type 3. These were initially isolated in an epithelial cell line derived from human embryo lung (HEL) (Davis and Bolin, 1960) and subsequently maintained frozen at $-70^{\circ} \mathrm{C}$ at the NCDC Phoenix Field Station laboratories. They were sent to London in ampoules on dry ice and of arrival were immediately stored at $-55^{\circ} \mathrm{C}$. In Londog passage of the viruses used for the present study was carried out only in primary human embryo liver cellss Cultures were harvested when extensive cytopathic effee was evident. Cells, together with the supernatant fluidg were pooled and then rapidly frozen and thawed thre times. The cell debris was removed by light centrifugation in the cold at $1,500 \mathrm{rpm}$ for five minutes before dispensing into ampoules which were then stored at $-55^{\circ} \mathrm{C}$ unt required.

Titration of the viruses was carried out in cultures embryo liver cells. Serial virus dilutions were made phosphate buffered saline at $p \mathbf{H} 7 \cdot 2$, and $0.1 \mathrm{ml}$ volumes were inoculated into each tissue culture cup. Readings 
were taken 72 hours after inoculation by examination of preparations stained with $1 / 1,000(\mathrm{w} / \mathrm{v})$ solution of

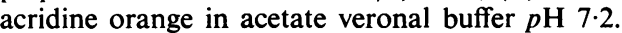

Monolayers of embryo hepatocytes were inoculated with $0.1 \mathrm{ml}$ of $10^{-2}$ dilution of the virus suspension. For electron microscopy cell monolayers were fixed 48 and 72 hours after infection with $3 \%$ glutaraldehyde and $1 \%$ osmium tetroxide using Rhodin and Zetterquist buffer in both cases. During dehydration the preparations were stained for 10 minutes in $1 \%$ tungstophosphoric acid in absolute ethanol. Control preparations from the same liver were prepared in the same way. Sections were cut on a Huxley type, Cambridge Instrument Company, ultramicrotome and viewed in an A.E.I. EM6 electron microscope. Micrographs were taken on Ilford special lantern contrasty plates at $\times 16$ to 40,000 magnification.

\section{RESULTS}

The appearances of normal embryo hepatocytes, as seen by phase contrast light microscopy and by fluorescence microscopy, are shown in Figs. 1 and 2 and are as described previously by Zuckerman et al (1967b). The morphology of such cells on low power electron microscopy is illustrated in Figure 3. Details

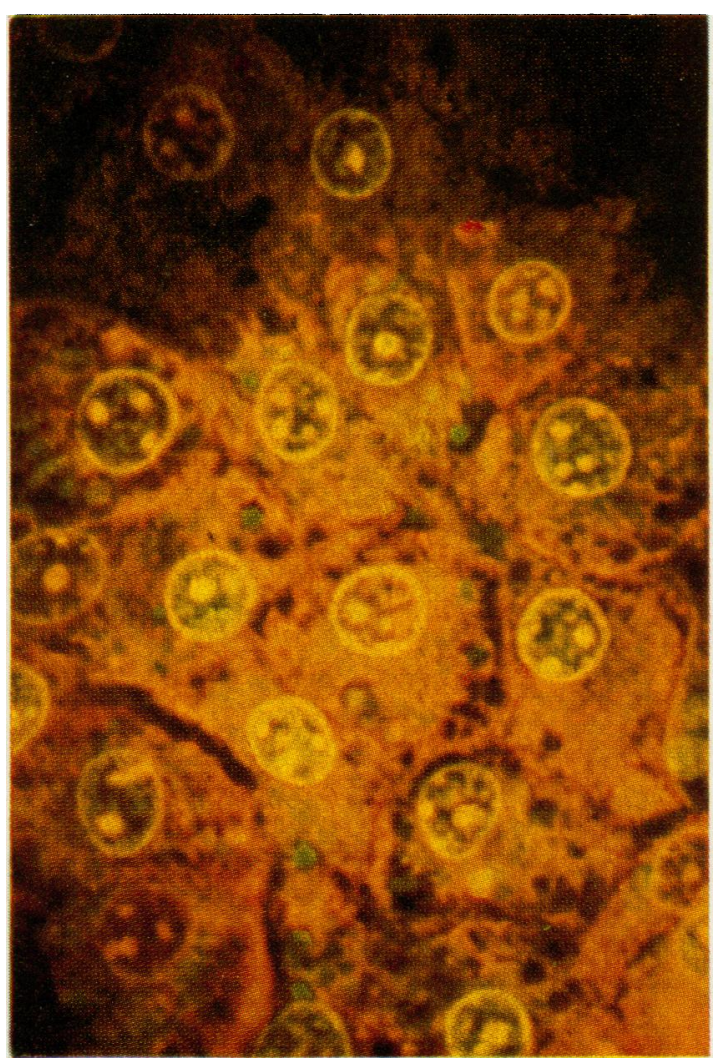

FIG. 1. of a typical area, at higher magnification, including portions of both nucleus and cytoplasm, can be seen in Figure 4. The characteristic cytopathic effects in the hepatocytes, as observed by fluorescence microscopy, after infection with SC-6 are shown in Figure 5.

The cells depicted in Figs. 6 and 7 show late stages of infection with SC-8 and SC-49 respectively. Cytopathic changes in the nucleus are apparent and there is striking fatty degeneration of the cytoplasm. Single virions and crystalline arrays are present both in the nucleus and in the cytoplasm. Notable among the other interesting features seen in these infected cells is the presence of both complete and incomplete virions in areas of apparent intense protein synthesis with high concentrations of cytoplasmic ribosomes interlaced by tonofibrils and microtubules together with the outlines of granular cytoplasmic membranes (Figs. 8 and 10). Figure 9 shows in greater detail the proximity of virion formation to elements of the granular reticulum. Few healthy mitochondria remain, and lysosome-like bodies are present in both nucleus and cytoplasm (Fig. 7). Where virus particles

FIG. 1. Normal embryo hepatocytes by fluorescence microscopy. The polygonal shape of the hepatocytes and their arrangement around bile canaliculi is particularly well shown. The cells are arranged in a monolayer. $\times 900$.

FIG. 2. Group of hepatocytes embedded as a monolayer in Araldite and selected by phase contrast microscopy from among the clusters of surrounding spindle-shaped cells. $\times 125$.

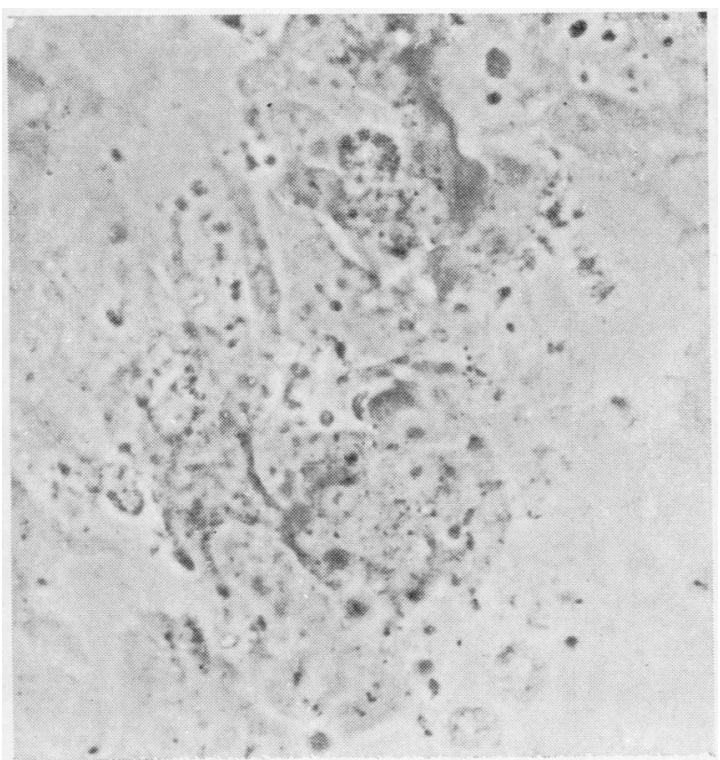

FIG. 2. 


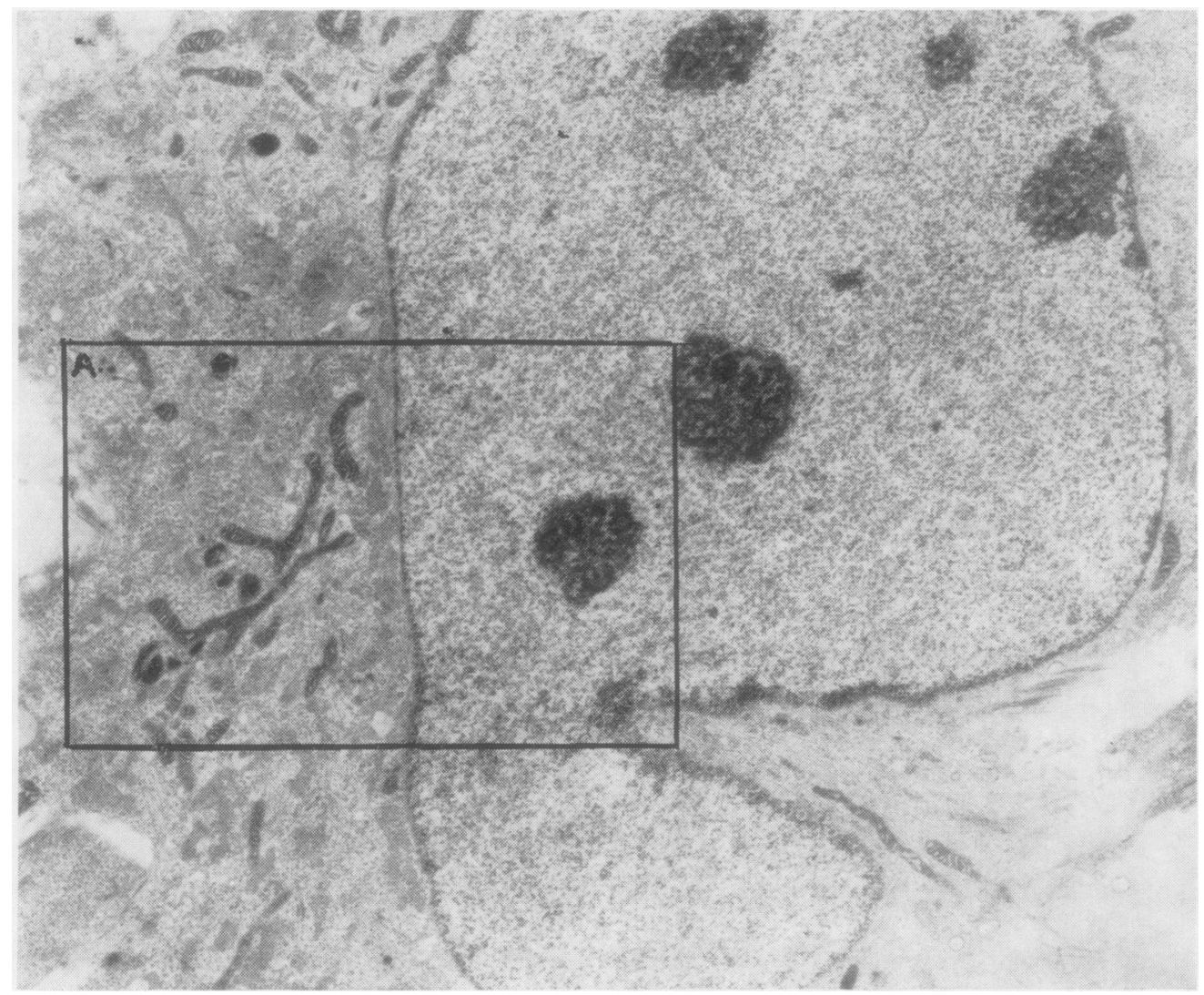

FIG. 3. Low power electron micrograph $(\times 3,000)$ of a control embryo hepatocyte fixed with glutaraldehyde and osmiumtetroxide then stained with tungstophosphoric acid. A large lobulated nucleus is surrounded by a narrow area of cytoplasm containing branching mitochondria.

are aggregated (Fig. 11) an unusual feature of the crystalline array is the apparent absence of a dense central core in the majority of virions. The cytopathic changes caused by SC-3 and SC- 6 were similar in all respects. There were no distinguishing features between the four strains under study. Measurements of the hexagonal virion contour gave an average size of 65 to $70 \mathrm{~m} \mu$ but careful search revealed occasional areas where this predominant type of virion contour appeared to be associated with a smaller satellite virus particle with a dimension of 30 to $40 \mathrm{~m} \mu$ (Fig. 12, note the inserts at higher magnification demonstrating clearly the two particle sizes).

\section{DISCUSSION}

This study was undertaken because of significant differences between the San Carlos viruses and the prototype adenovirus strains and also to examine the possibility of the existence of a second associated independent virus particle. Antigenic disparitis were revealed by serological tests, but such differences have been noted before within the adenovirus group and are not understood (Parks, Queiroga, Melnick and Pereira, 1967). Physical differences were suggested by thermal inactivation studies which showed that the prototype adenovirus 3 strain w\& inactivated by heating for 10 to 15 minutes at $50^{\circ} \mathrm{O}$ whereas the San Carlos strains resisted heating fop 40 minutes at $60^{\circ} \mathrm{C}$. Differences in cytopathology of the whole are not reliable but again support the existence of a disparity between the strains. Howevef, the differences from typical adenoviruses were eve more marked when viewed by electron microscopts

A notable feature of the examination by the electron microscope is the lack of a dense central cone in the majority of the San Carlos virions. This couf be postulated to be due to the influence of variations in the techniques of fixation on the appearance of 

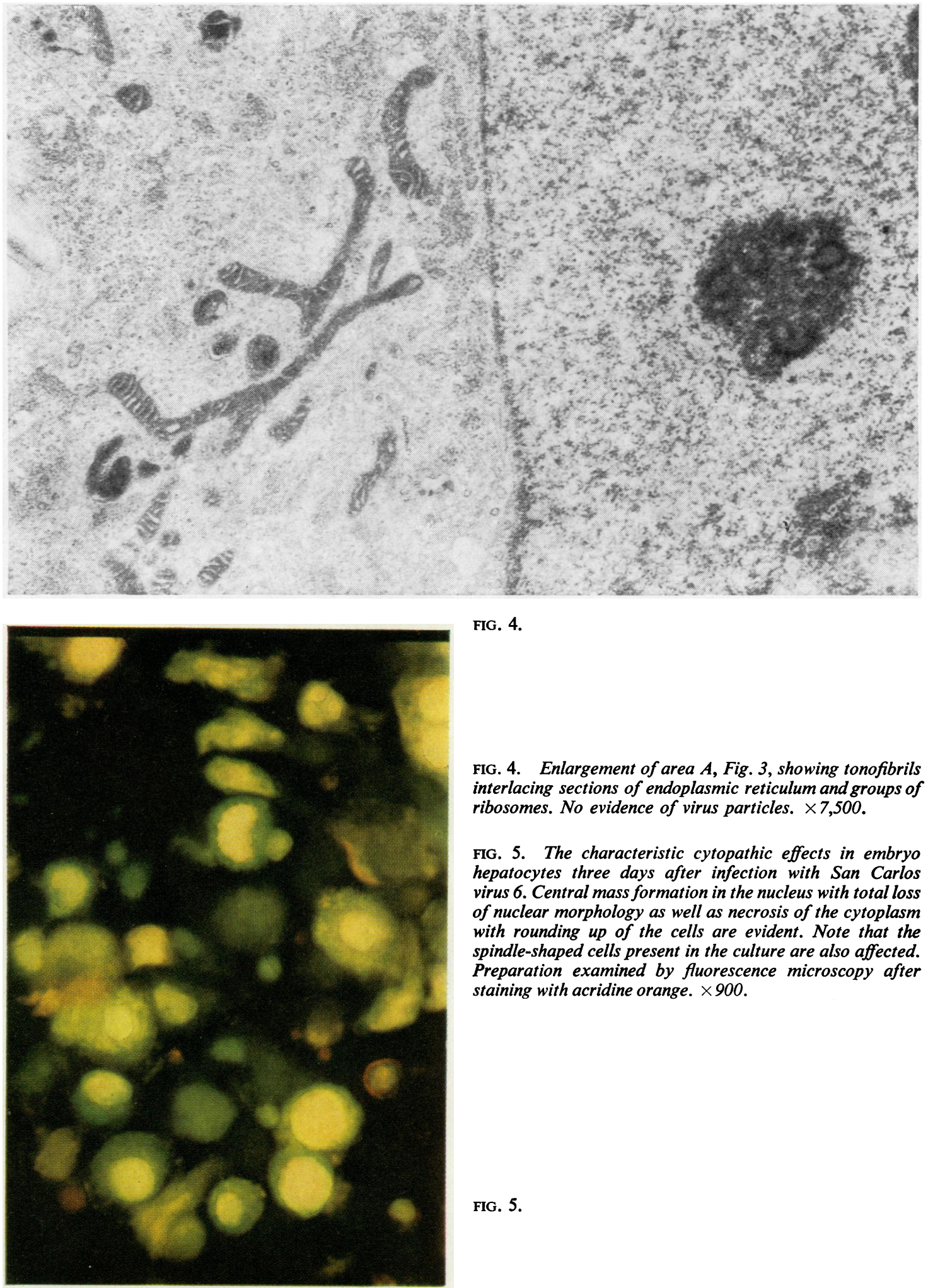

FIG. 4.

FIG. 4. Enlargement of area A, Fig. 3, showing tonofibrils interlacing sections of endoplasmic reticulum and groups of ribosomes. No evidence of virus particles. $\times 7,500$.

FIG. 5. The characteristic cytopathic effects in embryo hepatocytes three days after infection with San Carlos virus 6. Central mass formation in the nucleus with total loss of nuclear morphology as well as necrosis of the cytoplasm with rounding up of the cells are evident. Note that the spindle-shaped cells present in the culture are also affected. Preparation examined by fluorescence microscopy after staining with acridine orange. $\times 900$. 


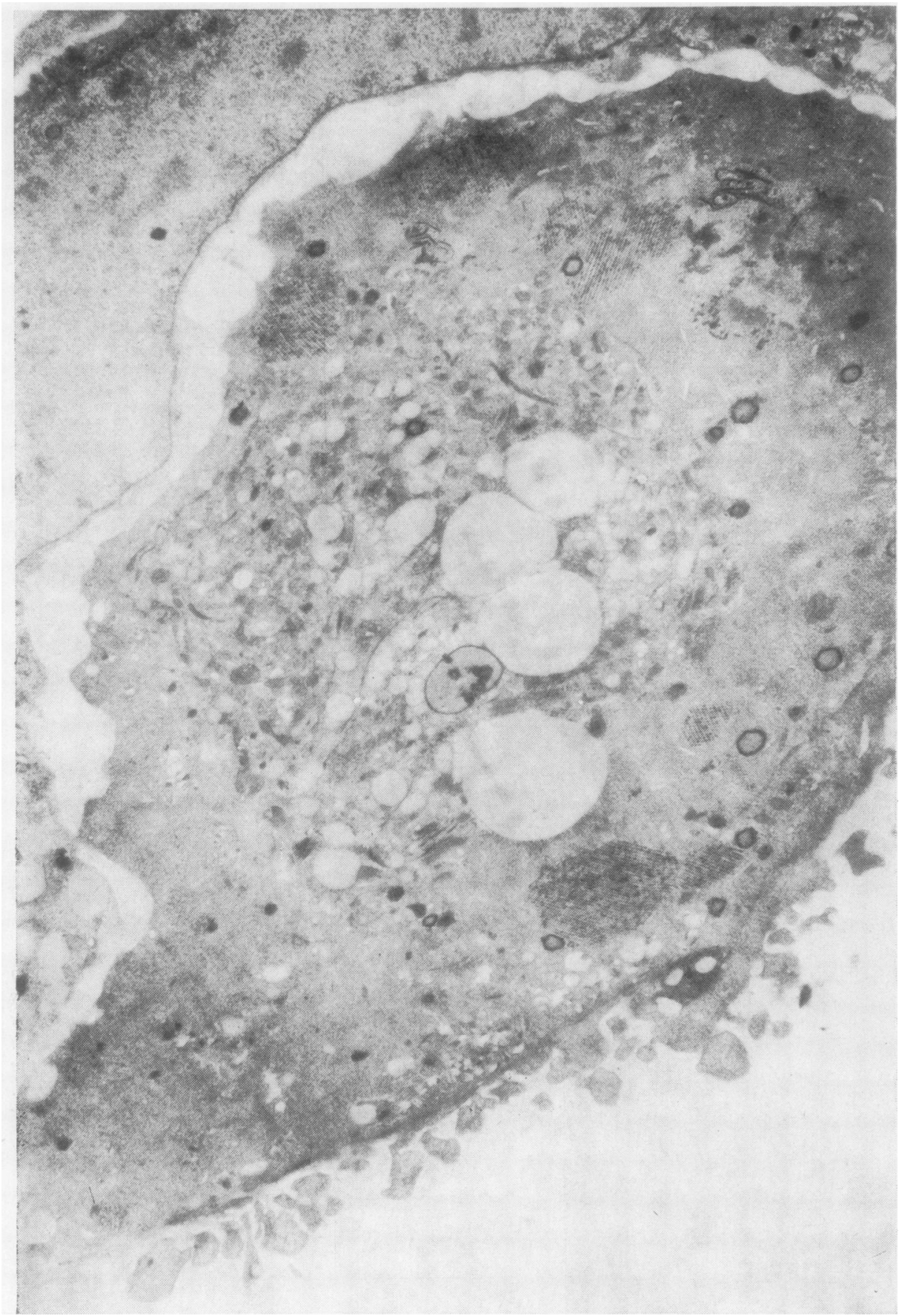

FIG. 6. An SC-8-infected hepatocyte, late stage, showing fatty vacuolation of nucleus and multiple crystalline arrays of virus particles arranged around the periphery of the cell. $\times 4,500$. 


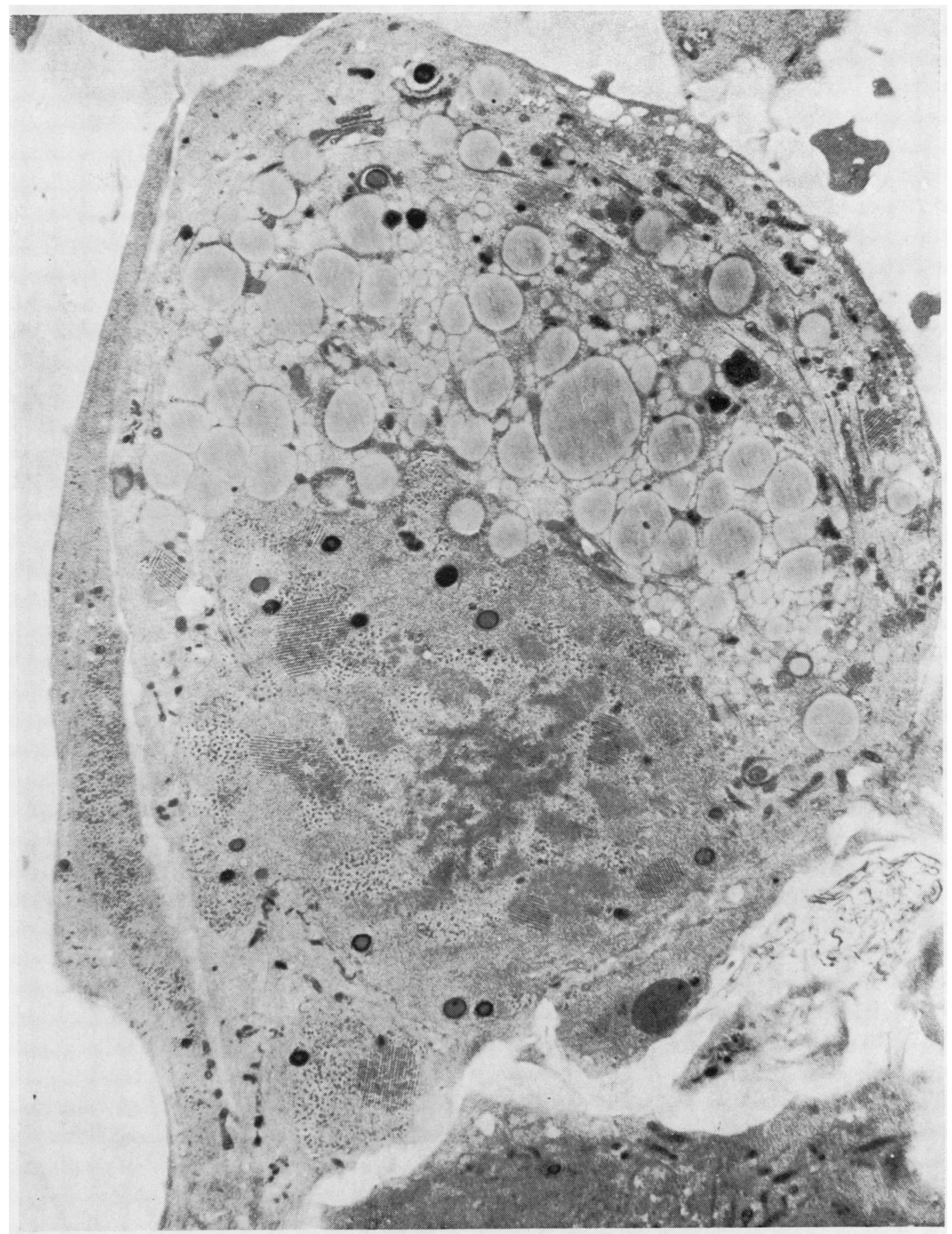

FIG. 7. An SC-49 infected hepatocyte, late stage, with marked fatty vacuolation of the cytoplasm and crystalline arrays of virus particles present in nucleus and cytoplasm. $\times 3,000$. 


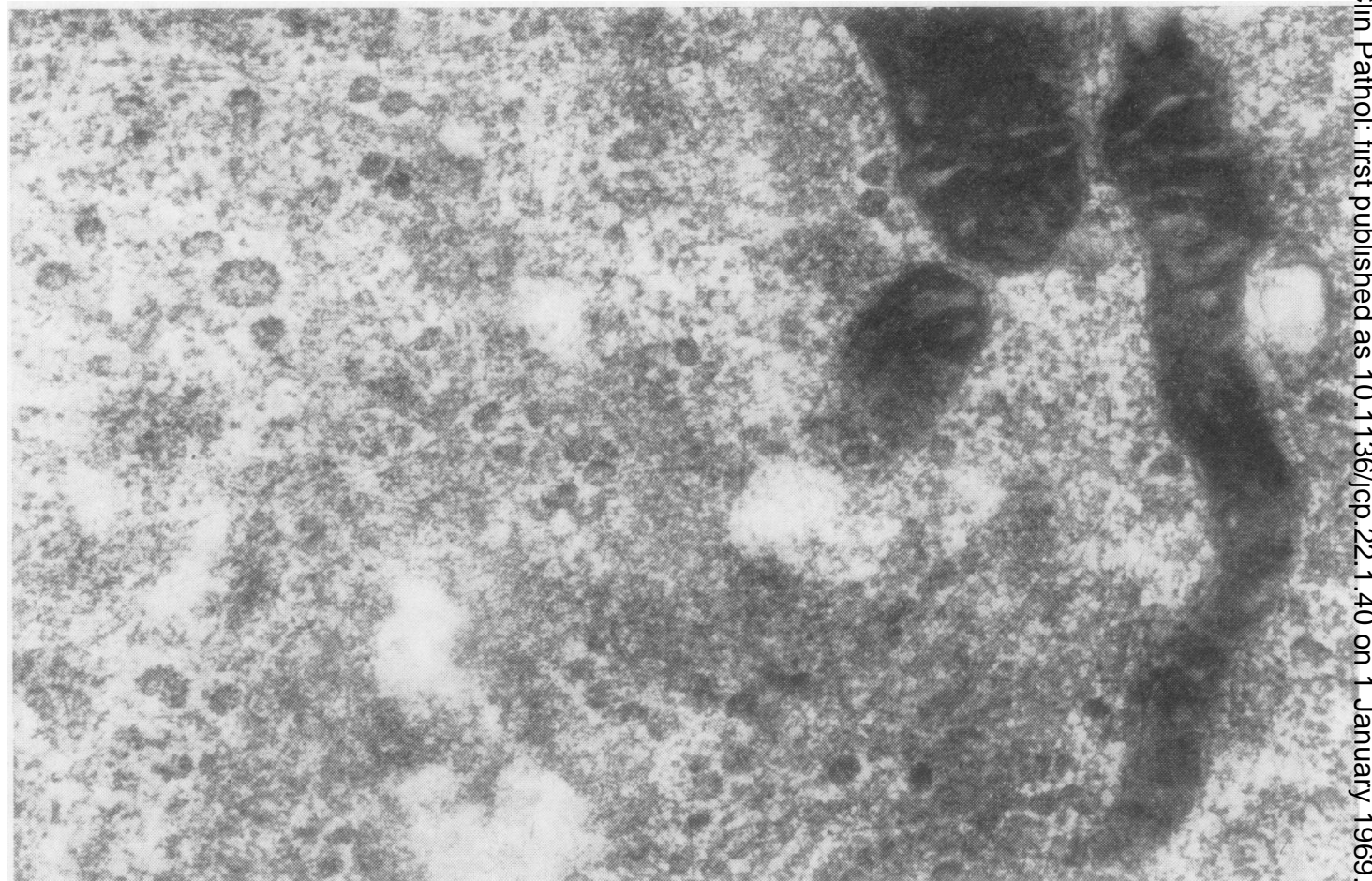

FIG. 8. Scattered virions among the microtubules, tonofibrils and ribosomes in the cytoplasm of an SC-8 infected hepatocyte. $\times 60,000$.



FIG. 9. The edge of a crystalline array of virions, some apparently lacking a central core, in the cytoplasm of another SC-49 infected cell. Single and small groups of virus particles are seen in association with strandes of endoplasmic reticulum and dense irregular masses of ribosomal material. $\times 48,000$. 


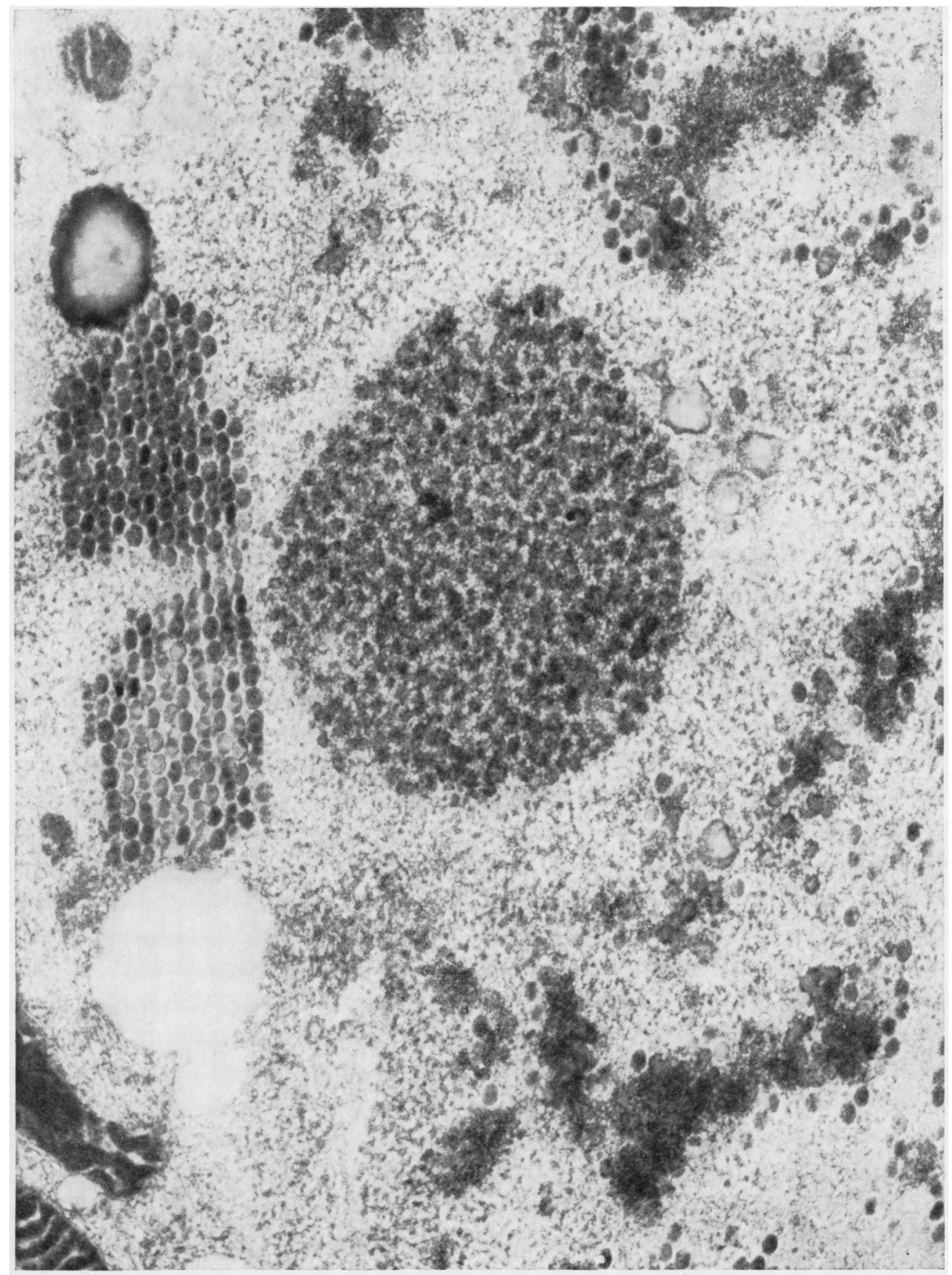

FIG. 10. A crystalline array and scattered virions in the same cell as in Fig. 9 (SC-49 infected). Both complete and incomplete virions are seen in an area of apparently intense protein synthesis. $\times 64,000$. 


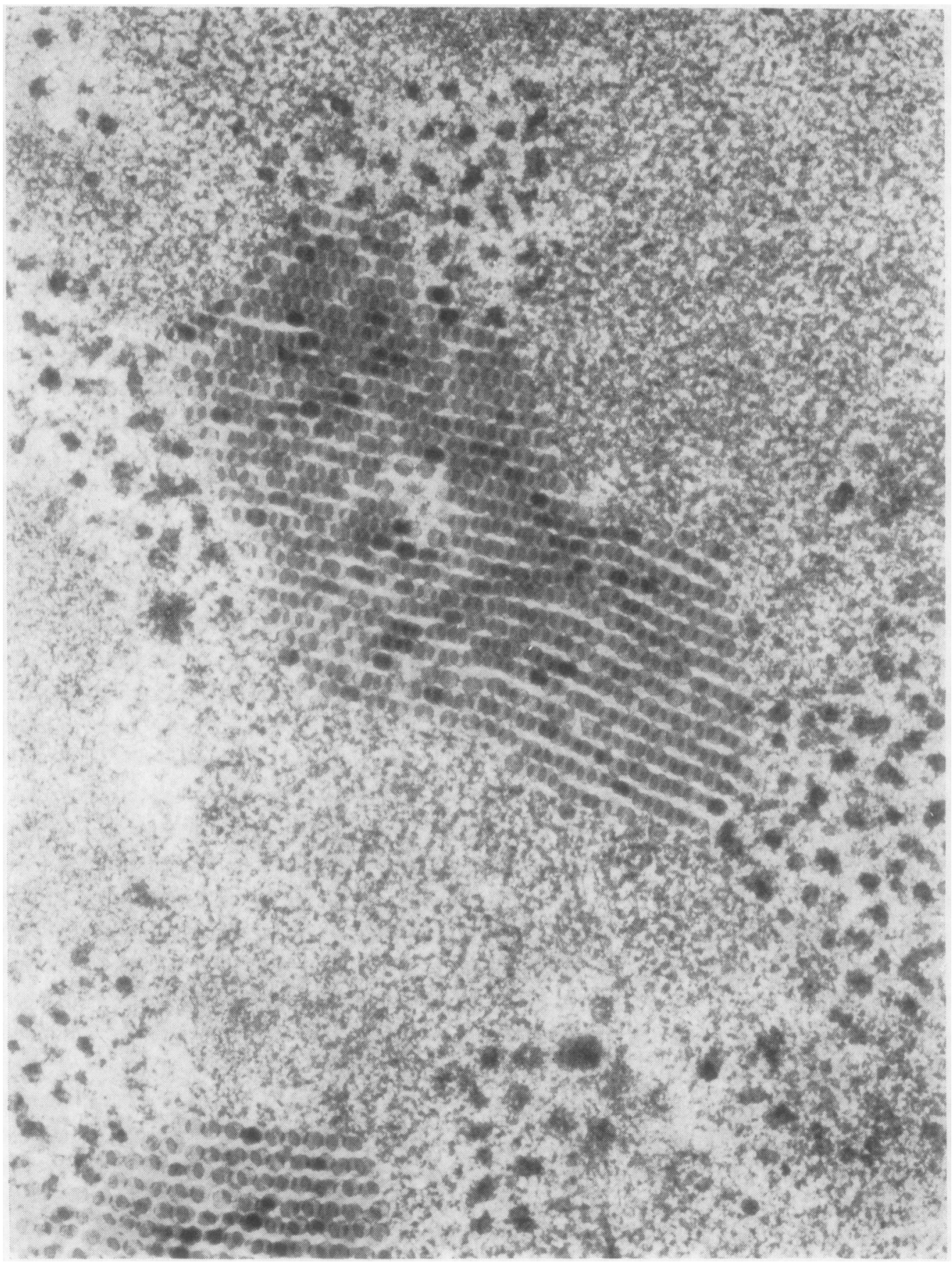

FIG. 11. Evidence of the active formation of a crystalline array at the time of fixation in an SC-49 infected cell. $\times 64,000$. 




FIG. 12 An SC-6 infected cell in which two types of virus particles can be distinguished. $(A)$ the larger average size 65 to $70 \mathrm{m \mu}$ and $(B)$ the smaller average size 30 to $40 \mathrm{~m} \mu$. 
viruses in thin sections (Peters and Büttner, 1965), but this is not our experience with the technique employed in the present study using prototype adenovirus strains. The use of uranyl acetate as a staining agent did not increase the number of cores. A striking observation is the apparent association of the virus particles with RNA elements, flattened membrane formations, and areas of ribosomal aggregation. This association suggested the possibility of infection of the hepatocytes with strains of reovirus, but this was excluded by the results of cross-neutralization tests employing monospecific antisera to reovirus types 1,2 , and 3 .

Evidence suggesting that the San Carlos 8 strain might be a mixture of two viruses was kindly made available by Hartwell and Aurenheimer ${ }^{1}$. Careful search of cultured human embryo hepatocytes by electron microscopy revealed no evidence of the presence of smaller virus particles in the cells infected with this particular strain. However, with the strain SC-6, two virion types of markedly different size were present. Our failure to demonstrate such associated smaller agents among the other strains might have been due to loss of the infective particles on passage in tissue culture, although examination of cells infected with the seed virus on first passage also did not reveal a second agent. Another possibility to be considered is that the smaller agent in these cases penetrated the cell but became 'masked', a situation similar in many ways to the state of lysogeny. However, our attempts to induce such agents from the hepatocytes by techniques similar to those that had been used for the induction of bacteriophages from lysogenic bacteria have not been successful (Zuckerman, 1968). The nature of the second virion type found in association with SC-6 is not yet clear. Its size of 30 to $40 \mathrm{~m} \mu$ is certainly much larger than the diameter of 22 to $24 \mathrm{~m} \mu$ which has been found with the known adeno-associated viruses (AAV) (Mayor, Jamison, Jordan, and Melnick, 1965; Atchison, Casto, and Hammon, 1965; Smith, Gehle, and Thiel, 1966; Hoggan, Blacklow, and Rowe, 1966; Atchison, Casto, and Hammon, 1966). The size of this second virion is probably also too large for it to be a candidate for the hepatitis virus, although different workers have described particles with diameters ranging from 12 to $18 \mathrm{~m} \mu$ (Rightsel, Keltsch, Taylor, Boggs, and McLean, 1961) to 40 to $60 \mathrm{~m} \mu$ (Braunsteiner, Fellinger, Pakesch, Beyreder, Grabner, and Neumayr, 1957; Gueft, 1961). Currently attempts are being made in the laboratory to separate the two agents so as to enable us to examine the properties of each virus separately.

'Of the NCDC, Phoenix, Arizona.
Finally, the possible role of infection with the San Carlos viruses in the aetiology of infectious hepatitis in man, especially in association with second agent which is as yet not fully characterized should be examined. The association of adenovirus

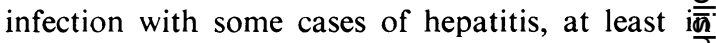
Arizona, should not be overlooked (Hartwell, Lov $\bar{\oplus}$ and Eidenbock, 1966) and mechanisms which may involve adenoviruses and precipitate the clinicál syndrome of hepatitis have been reviewed (Stron $\vec{B}$ 1965; Zuckerman, Alwen, and Fulton, 1967a). It i⿱宀 also interesting that Douglas and Berge (1964) notes that inoculation of chimpanzees with the San Carlos $\overrightarrow{8}$ virus caused elevation of the serum transaminases some of the animals as well as histological evidence of liver damage. However, it is not claimed that the San Carlos viruses are the causative agents of infectious hepatitis per se, but the possibility that second smaller agent may be associated with these strains, either in the form of a defective virus o@ indeed, as an independent agent, are being explore

We wish to thank Dr H. E. M. Kay and members of hig staff at the Tissue Bank of the Royal Marsden Hospitas Dr H. G. Pereira, London, and Dr C. M. P. Bradstree, of the Standards Laboratory for Serological Reagente Public Health Laboratory Service, Colindale, for the supply of adenovirus strains and antisera. We are als grateful to Professor A. P. Waterson, Mrs June Almeida and $\operatorname{Dr}$ A. J. Armstrong.

Part of this work was supported by a generous graif from the Medical Research Council.

\section{REFERENCES}

Atchison, R. W., Casto, B. C., and Hammon, W. M. (1965). Scient 149, 754.

- - - - - (1966). Virology, 29, 353.

Braunsteiner, H., Fellinger, K., Pakesch, F., Beyreder, p' Grabner, G., and Neumayr, A. (1957). Wien. Z. inn. Med., 38 231.

Davis, E. V. (1961). Science, 133, 2059.

—, and Bolin, V. S. (1960). Fed. Proc., 19, 386.

Douglas, J. D., and Berge, T. O. (1964). In Amer. vet. med. A.0 sci. Proc. Ann. Mtg, 101, p. 243.

Gueft, B. (1961). Arch. Path., 72, 61

Hartwell, W. V., Love, G. J., and Eidenbock, M. P. (1966). Scien $152,1390$.

Hatch, M. H., and Siem, R. A. (1966). Amer. J. Epidemiol., 84, 4955 Hoggan, M. D., Blacklow, H., and Rowe, W. P. (1966). Proc. nd? Acad. Sci. (Wash.), 55, 1467.

Mayor, H. D., Jamison, R. M., Jordan, L. E., and Melnick, J. (1965). J. Bact., 90, 235.

Parks, W. P., Queiroga, L. M., Melnick, J. L., and Pereira, H. (1967). Proc. Soc. exp. Biol. (N.Y.), 125, 498.

Peters, D. H. A., and Büttner, D. (1965). Lab. Invest., 14, 2.

Rightsel, W. A., Keltsch, R. A., Taylor, A. R., Boggs, J. B., a McLean, I. W. D. (1961). J. Amer. med. Ass., 177, 671.

Smith, K. O., Gehle, W. D., and Thiel, J. F. (1966). J. Immunol., 97, 754.

Strong, W. B. (1965), CDC Hepatitis Surveillance Reports, no. 22, p. 17 Zuckerman, A. J., (1968). Acta hepatosplenolog.. 15, 109.

-.. Alwen, J., and Fulton, F. (1967a). Nature (Lond.), 214. 606. \ृ , Dunkley, L. J., and Love, G. J. (1968). Brit.J. exp. Path., 茹 235.

, Tsiquaye, K. N., and Fulton, F. (1967b). Brit. J. cxp. Patte 48. 20 . 